Patrick C. Leyens

\title{
Informationsintermediäre des Kapitalmarkts
}

Private Marktzugangskontrolle durch Abschlussprüfung, Bonitätsrating und Finanzanalyse

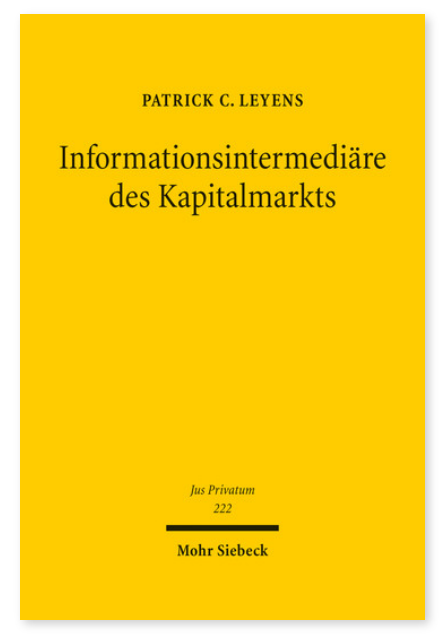

2017. XLII, 841 Seiten. JusPriv 222

ISBN 978-3-16-154097-4

DOI 10.1628/978-3-16-154097-4

eBook PDF 149,00€

ISBN 978-3-16-154096-7

Leinen $149,00 €$
Informationsintermediäre des Kapitalmarkts vermitteln zwischen Unternehmen, Aktionären und Investorenpublikum. International gelten sie als Institutionen einer privaten Marktzugangskontrolle (gatekeeping). An Abschlussprüfung, Bonitätsrating und Finanzanalyse werden die wirtschaftliche Funktionsweise und das Spektrum rechtlicher Wirkungen deutlich.

Patrick C. Leyens zeigt die wachsende Bedeutung der privaten Informationsintermediation am Kapitalmarkt auf. Er erschließt die entstehungsgeschichtlichen, ökonomischen und regulierungstheoretischen Grundlagen der privaten Marktzugangskontrolle. Die daraus entwickelten Anforderungen an das Recht der kapitalmarktlichen Informationsintermediation reichen über die gewählten Referenzgebiete hinaus. Die Vorschläge zu Recht und Reform betreffen das Vertragsrecht, die Partei- und Dritthaftung sowie die berufsrechtlichen und regulatorischen Pflichten.

Patrick C. Leyens ist Professor für Bürgerliches Recht, Handels- und Gesellschaftsrecht an der Universität Bremen und ehrenamtlicher Professor für Law and Economics an der Erasmus Universität Rotterdam.

https://orcid.org/0000-0002-3543-5587
Jetzt bestellen:

https://mohrsiebeck.com/buch/informationsintermediaere-des-kapitalmarkts-9783161540974?no cache=1 order@mohrsiebeck.com

Telefon: +49 (0)7071-923-17

Telefax: $+49(0) 7071-51104$ 